\title{
Sleeping well
}

\author{
Mithu Sen and G Bryan Young*
}

See related research article here http://www.biomedcentral.com/1741-7015/11/18

Abstract
In a study by Cruse et al. published in BMC Medicine,
patients with severe brain damage who were in the
Vegetative or Minimally Conscious States (VS or MCS,
respectively) from traumatic and nontraumatic
etiologies had assessments of circadian rhythms using
an actigraph, a device worn on a limb to evaluate
circadian rhythmicity, in this population. This is a
novel approach and is being used as a surrogate for
polysomnography and other reference standards.
Cruse et al. showed more disruption in circadian
rhythms in the VS when compared to the MCS. This
suggests that more brain injury occurs in the areas
that control circadian rhythmicity in VS than in MCS
patients. The study provides opportunities for
improved prognostication and rehabilitation strategies
in this patient population.
Keywords: vegetative state, minimally conscious
state, actigraphy, circadian rhythm

\section{Commentary}

Sleep is the golden chain that ties health and our bodies together. (Thomas Dekker)

The Vegetative and Minimally Conscious States (VS and MCS, respectively) are severe disorders of consciousness that reflect severe brain dysfunction/damage. Vegetative patients have preserved vegetative functions (temperature, hemodynamic and hormonal regulation and breathing) and are awake (with arousability with eye opening and sleep-wake cycles) but show no behavioral evidence of awareness (no eye contact, tracking, obeying of commands or emotional responses). Minimally conscious patients show minimal and limited but definite evidence of some aspect(s) of awareness, for example, visual tracking, movements or emotional responses triggered by relevant environmental stimuli, even very

\footnotetext{
* Correspondence: bryan.young@lhsc.on.ca

Department of Medicine, Division of Critical Care Medicine, Western University, London, Ontario, N6A 5A5, Canada
}

simple command-following or verbalization as isolated phenomena.

Cruse and colleagues report the results of actigraphy assessments of circadian sleep-wake rhythms in patients with VS and MCS in research published in BMC Medicine [1]. They studied patients with traumatic and nontraumatic brain injury at widely ranging intervals from the ictus (0 to 290 months). Actigraphy uses a watchshaped device that is strapped to the arm and is used to measure limb movements in sleep as a surrogate for estimating the sleep-wake cycle. The actigraphs (or actimeters) can provide patterns of activity that can be used to outline circadian rhythms [2]. Four distinct aspects of movement are captured: amplitude, acrophase (the point in the sleep-wake cycle when activity is maximal), the mesor (the mean of the rhythm) and a goodness-of-fit curve to show the robustness of the circadian rhythm. This methodology has been previously validated by comparing the results with standard polysomnography [2].

The principal finding was that as a group VS patients ( $\mathrm{n}=18$ ) had more significantly disrupted circadian rhythms than did MCS patients ( $\mathrm{n}=37$ ).

There may be theoretical advantages and disadvantages in using actigraphy in this population instead of reference standards of objective measures, such as formal polysomnography or dim-light melatonin onset, or subjective measures, such as sleep log [3]. There was considerable heterogeneity in the anatomy and severity of the brain damage among the patients. Polysomnographic sleep staging relies primarily on the electroencephalographic (EEG) changes over time along with other variables. The EEG records rhythms from the cerebral cortex. The cortex may be somewhat dissociated from subcortical structures, namely the hypothalamus and thalamus, which drive the sleep-wake cycle, especially in cases of severe head injury with diffuse axonal injury. Thus, actigraphy, which reliably measures the motor output of various sleep and wakefulness stages, may have an advantage. On the other hand, if the motor pathways are damaged, this may dissociate motor output from activity of the deep grey structures.
C Biomed Central

() 2013 Sen and Young; licensee BioMed Central Ltd. This is an Open Access article distributed under the terms of the Creative Commons Attribution License (http://creativecommons.org/licenses/by/2.0), which permits unrestricted use, distribution, and reproduction in any medium, provided the original work is properly cited. 
There were confounders present, especially the use of drugs that could alter the EEG, sleep-wake cycle including sleep staging, but at least these were well documented.

The findings of Cruse et al. [1] are of both theoretical and practical interest. It makes intuitive sense that circadian rhythms would be more disrupted in patients with VS than MCS as the former state reflects a greater degree of brain damage than the latter. As the authors mention, the suprachiasmatic nucleus in the thalamus (the 'pacemaker' for the circadian rhythm) need not be directly damaged to produce circadian disruption, but is driven to some extent by other structures, especially the thalamus [4], which is commonly damaged directly or through transsynaptic degeneration [5]. It follows that the degree of circadian rhythm disruption as measured by actigraphy, in this novel application, may have prognostic significance. The other point, which seems to be making itself more apparent with advances in technology, is that the clinical evaluation in severely braindamaged patients is often inaccurate or misleading [6,7]. Simple eye-opening to differentiate wakefulness from sleep is not always reliable.

There are some exciting prospects for extending this type of research. Combining polysomnography with actigraphy may address the variable pathologies in braininjured patients and allow better characterization and validation of sleep compared to wakefulness. It would also be of value to study patients serially from the time of ICU admission onwards to note when true sleep-wake circadian cycles return and to correlate these with other measures of structure and function to arrive at an earlier prognosis. This may also help in the selection of patients who could be fast-tracked for early rehabilitation, which has been shown to improve cognitive and discharge destination outcomes [8].

\footnotetext{
Abbreviations

EEG: electroencephalographic; MCS: Minimally Conscious State; VS:

Vegetative State.
}

\section{Competing interests}

The authors declare that they have no competing interests.

Authors' contributions

MS and GBY drafted the editorial and have read and approved the final manuscript.

\footnotetext{
Authors' information

MS is an Associate Professor in the Department of Medicine, Divisions of Critical Care Medicine and Respirology/ Sleep Medicine and Schulich School of Medicine and Dentistry, Western University, London, ON, Canada. She is certified in sleep medicine and is a Fellow of the American Academy of Sleep Medicine (FAASM) as well as board certified in Critical Care and Pulmonology in both Canada and the US. She is the Director of Education for the Royal College of Physicians and Surgeons of Canada (RCPSC) Postgraduate Residency Training Program for Adult Critical Care, Western University. GBY is a Professor in Clinical Neurological Sciences specializing in neurocritical care.
}

Received: 17 December 2012 Accepted: 24 January 2013 Published: 24 January 2013

\section{References}

1. Cruse D, Thibaut A, Demertzi A, Nantes JC, Bruno M-A, Gosseries O, Vanhaudenhuyse A, Nekinschtein TA, Owen AM, Laureys S: Actigraphy assessments of circadian sleep-wake cycles in the vegetative and minimally conscious states. BMC Med.

2. Jean-Louis G, von Gizycki H, Zizi F, Spielman A, Hauri P, Taub H: The actigraph data analysis software: I A novel approach to scoring and interpreting sleep-wake activity. Percept Mot Skills 1997, 85:207-216.

3. Morgenthaler T, Alessi C, Friedman L, Owens J, Kapur V, Boehlecke B, Brown T, Chesson A Jr, Coleman J, Lee-Chiong T, Pancer J, Swick TJ: Practice parameters for the use of actigraphy in the assessment of sleep and sleep disorders: an update for 2007. Sleep 2007, 30:519-529.

4. Schiff ND: Central thalamic contributions to arousal regulation and neurological disorders of consciousness. Ann N Y Acad Sci 2008, 1129:105-118.

5. Fernandez-Espejo D, Junque C, Bernabeu M, Roig-Rovira T, Vendrell P, Mercader JM: Reductions in thalamic volume and regional shape changes in the vegetative and the minimally conscious states. J Neurotrauma 2010, 27:1187-1193.

6. Owen AM, Coleman MR, Boly M, Davis MH, Laureys S, Pickard JD: Detecting awareness in the vegetative state. Science 2006, 313:1402.

7. Cruse D, Chennu S, Chatelle C, Bekinschtein TA, Fernandez-Espero D, Pickard JD, Laureys S, Owen AM: Bedside detection of awareness in the vegetative state - a cohort study. Lancet 2011, 378:2088-2094.

8. Mackay LE, Bernstein BA, Chapman PE, Morgan AS, Milazzo LS: Early intervention in severe head injury: long-term benefits of a formalized program. Arch Phys Med Rehabil 1992, 73:635-641.

\section{Pre-publication history}

The pre-publication history for this paper can be accessed here: http://www.biomedcentral.com/1741-7015/11/19/prepub

\section{doi:10.1186/1741-7015-11-19}

Cite this article as: Sen and Young: Sleeping well. BMC Medicine 2013 11:19.

\section{Submit your next manuscript to BioMed Central and take full advantage of:}

- Convenient online submission

- Thorough peer review

- No space constraints or color figure charges

- Immediate publication on acceptance

- Inclusion in PubMed, CAS, Scopus and Google Scholar

- Research which is freely available for redistribution

Submit your manuscript at www.biomedcentral.com/submit 